\title{
PROCESSO DE CONVERSÃO E DESCONVERSÃO POLÍTICO-RELIGIOSA ENTRE JUDEUS E NEOPENTECOSTAIS CONSERVADORES
}

\author{
Olga Christina de Oliveira Zunino'
}

RESUMO: Este artigo encontra-se na fase das análises relacionadas a economia, relações sociopolíticas e religiosas da contemporaneidade. Ele se propõe apresentar uma reflexão sobre como a conjuntura política e econômica atual está desenvolvendo a aproximação externa e o afastamento interno de atores políticos dentro do campo neopentecostal e judaico. Para isso, são apresentados os conceitos de conversão e desconversão, estes desenvolvidos a partir da observação do campo, como o resultado de um processo político fundamentado na unificação de judeus e neopentecostais conservadores em uma nova comunidade políticoreligiosa. Para isso, a pesquisa baseia-se na metodologia qualitativa, utilizando-se de técnicas como análise documental e etnografia.

PALAVRAS-CHAVE: identidade política; religiosidade; nova direita.

\section{POLITICAL-RELIGIOUS PROCESS OF CONVERSION AND DECONVERSION BETWEEN CONSERVATIVE JEWS AND NEOPENTECOSTALS}

${ }^{1}$ Graduanda em Ciências Sociais pela Universidade Federal do Rio de Janeiro. Pesquisadora no Núcleo Interdisciplinar de Estudos Judaicos e Árabes (NIEJ) e do Núcleo de Estudos da Cidadania, Conflito e Violência Urbana (NECVU) e bolsista da Fundação de Amparo à Pesquisa do Estado do Rio de Janeiro (FAPERJ).

\begin{abstract}
This article is at the stage of analyzes related to the economy, socio-political and religious relations of the contemporary world. He proposes to present a reflection on how the current political and economic conjuncture is developing the external approach and internal separation of political actors within the neoPentecostal and Jewish fields. For this, the concepts of conversion and deconversion is presented, developed from the observation of the field, as the result of a political process based on the unification of conservative Jews and neo-pentecostals in a new politicalreligious community. For this, the research is based on qualitative methodology, using techniques such as document analysis and ethnography.
\end{abstract}

KEYWORDS: political identity; religiosity; new right. 


\section{INTRODUÇÃOO}

"Não é a política que vai mudar esta nação, é a Igreja" (HOLANDA, 2018). Assim foi estampada a manchete no jornal Estadão em dezembro de 2018, reproduzindo a fala da atual ministra da Mulher, da Família e dos Direitos Humanos, Damares Alves, em meados de 2013, em uma palestra na Primeira Igreja Batista, em Campo Grande, no Rio de Janeiro. Essa fala foi citada para introduzir o leitor sobre o tipo de narrativa político-religiosa que será discutida no decorrer do artigo. Pretende-se com esse empreendimento introdutório discutir, refletir e apresentar os primeiros dados produzidos pela pesquisa até então. Para conseguir satisfatoriamente alcançar tal objetivo, o artigo primeiramente irá apresentar o debate na qual servirá de contexto para indicar o leitor à tese principal do artigo: Uma narrativa político-religiosa construída para analisar uma aliança estratégica com potencial para uma união comunitária de símbolos e paradigmas das duas religiões: o pentecostalismo, especialmente o neopentecostalismo, e o judaísmo.

É importante ressaltar que essa pesquisa pretende analisar a narrativa explorada por lideranças políticas nos veículos midiáticos, partindo da concepção de que ambas as comunidades aqui analisadas possuem em si mesmas uma pluralidade de perspectivas políticas e litúrgicas. Isto foi inclusive analisado no campo até então, observando declarações públicas de lideranças evangélicas contrárias a esse movimento político neopentecostal, como a Pastora Mônica Francisco, através também do movimento "Judeus pela Democracia" que auxiliou a definir o limite analítico pela qual é possível generalizar o discurso político aqui apresentado e estudado.

Ademais, a pesquisa pretende trabalhar com a análise das "três ondas" de Paul Freston (1994) para delimitar analiticamente os limites entre diferentes momentos do pentecostalismo no Brasil. É importante ressaltar que apesar de na análise de Freston essas ondas estarem temporalmente localizadas na histórica, atualmente é possível pensálas como "tipos ideais" que podem inclusive coexistir temporalmente e que os são muitas vezes. Portanto a interpretação escolhida para essa categorização será de interpretá-la como perfis de prática religiosa, como, por exemplo, a relação paradigmática com a Igreja Universal do 
Reio de Deus (IURD) com os veículos de comunicação o que não é visto em mesma escala em outras igrejas de caráter pentecostal clássico.

Por fim, a pesquisa irá se concentrar em três igrejas neopentecostais: A Igreja Universal do Reino de Deus, a Igreja Internacional da Graça de Deus (IIGD) e Igreja Mundial do Poder de Deus (IMPD), a razão para esta seleção se deve a três critérios: A produção de material acessível para a análise, à notoriedade que suas lideranças têm para os veículos midiáticos convencionais como os jornais tradicionais e a participação que as lideranças mais proeminentes tem na disputa política. Nesse artigo, os principais dados trabalhados serão os desenvolvidos por meio da análise documental de fontes secundárias, no caso de jornais, e primárias no caso da análise de material diretamente colhido do objeto observado, também será explorada uma experiência de campo.

Nesse sentido, é possível continuar expressando de qual contexto científico o artigo partirá para legitimar suas hipóteses. Entende-se que no Brasil como em países como Israel, Estados Unidos, Alemanha e Inglaterra ocorrem um momento de mudança paradigmática de como as lideranças políticas atuam no decorrer do jogo democrático, isso está embasado por escritos, por exemplo, de Mounk (2019), Levitsky e Ziblatt (2018), Przeworski (2019) e Levitsky e Way (2002). O que todas essas produções científicas debatem é sobre a emergência de um tipo de autoritarismo contemporâneo que atua por meio de representantes que atuam de forma a esvanecer gradualmente as divisões juridicamente postas e os valores democráticos para a manutenção de sua soberania. Na bibliografia alguns dos autores desenvolvem uma análise comparativa dos casos que comprovam o que foi compreendido como "escalada autoritária" ou uma "transição para uma democracia desprovida de valores liberais".

Esse artigo não discutirá com a mesma sensibilidade e detalhe sobre esses conceitos desenvolvidos, entende-se que esses conceitos são satisfatoriamente debatidos nos estudos apresentados. Portanto, essa pesquisa aproveitará das conclusões desses autores para compreender qual o papel dos representantes religiosos adeptos dessa 
narrativa política-religiosa, que será melhor discutida no decorrer do artigo, nesse movimento de relativização e banalização dos valores democráticos. Esse autoritarismo com potencial moralizante da vida política e social estaria sendo instigado pela entrada de lideranças religiosas com tendências fundamentalistas, isto é, com aversão ao ideal de laicidade ou essas lideranças fundamentalistas e sectárias estariam sendo beneficiadas por esse momento político internacional e assim sendo sua presença política seria uma consequência do mesmo?

Não se pretende com esse artigo responder integralmente perguntas com demandas por análises mais complexas, mas espera-se conseguir introduzir essas questões e prová-las como reflexões pertinentes para a atualidade. Por isso é possível que o artigo possa ter um caráter ensaístico, priorizando-se quando não há a produção competente de dados por uma abordagem teórica sólida para expressar pelo menos o quanto a reflexão apresentada possui fundamento científico mínimo. Portanto, com as pretensões e ambições do artigo devidamente delimitadas, é possível continuar com a apresentação da estrutura.

Como será discutido a partir desse contexto político anteriormente trabalhado, pretende-se por consequência compreender como a fé está localizada nessa ambientação política. A hipótese central do artigo diz respeito a uma transição de alianças politicamente estratégicas para uma comunidade baseada na formulação de um imaginário na qual integra tanto práticas quanto símbolos pentecostais quanto judaicos. Para conseguir estabelecer o fazer científico necessário para conseguir estudar a relevância dessa hipótese, será analisado no artigo as práticas religiosas desse neopentecostalismo. E aqui é possível fazer um adendo: o artigo dará maior relevância a atuação religiosa e política de neopentecostais conservadores e que estão de alguma forma beneficiando-se do contexto político apresentado, será despendido o esforço necessário para apresentar com responsabilidade o perfil do neopentecostal conservador para poder expressar a hipótese central com mais clareza.

Na leitura da bibliografia sobre o tema do neopentecostalismo foi ressaltado a presença do caráter econômico e litúrgico como motivador. Compreendo que a adesão contemporânea ao 
pentecostalismo no geral é complexa, como expresso quantitativamente pelo World Values Survey e o Pew Research Center na produção dos dados e nos trabalhos sociológicos que a respaldam, como por exemplo, o livro Tongues of fire: The explosion of Protestantism in Latin America de David Martin e Peter Berger (1990). Dessa forma, o artigo não despreza essa produção científica, mas concentra-se em explorar essas motivações apresentadas.

Portanto, neste texto irá se aprofundar inicialmente sobre o caráter litúrgico partindo do princípio que a adesão do pentecostalismo no Brasil, como na América Latina no geral, perpassa por essa capacidade flexível de assimilar práticas rituais de outras religiões já presentes. Assim, observará-lo a partir das lentes desse neopentecostalismo conservador. Quais são as consequências políticas dessa assimilação? Quais são as consequências religiosas dessa assimilação para as religiões "alvo" e para o próprio neopentecostalismo? Espera-se, portanto, entender como a narrativa neopentecostal conservadora operacionaliza essa motivação e como isso auxilia na criação do que a hipótese central defende: a criação de uma comunidade político-religiosa.

Em seguida, será discutida a motivação econômica da mesma forma como foi apresentado o contexto político que servirá de base para a pesquisa. A pesquisa compreende uma forma de atuação econômica que incorpora na vida política e social uma filosofia de mercado que encontra momentos de incongruência com a lógica democrática, pretende-se operacionalizar uma bibliografia para esse fim com o objetivo de alcançar o nível de debate analítico suficiente para compreender a faceta complexa desse neopentecostal conservador.

No final do artigo, será apresentado o perfil do judeu conservador, de forma a compreender como esse ator se articula com o neopentecostal e de como ele compreende essa dinâmica de assimilação. Para isso, revisitarei uma bibliografia para compreender como é constituída a identidade judaica no Brasil e a constituição da comunidade judaica no Brasil e em Israel. 


\section{NEOPENTECOSTALISMO E A EXTREMA-DIREITA: A CONSTRUÇÃO DE COMUNIDADES IMAGINÁRIAS}

Os neopentecostais analisados se orientam pela Teologia da Prosperidade ou Evangelho da Prosperidade, doutrina religiosa cristã que associa o sucesso financeiro ao desejo divino, os atores empregam essa doutrina de forma a desenvolver nos fiéis um sentimento positivo em relação ao pertencimento a comunidade religiosa. De acordo com o Pew Research Center, a conversão do fiel está relacionada com como o pentecostalismo desenvolveu práticas ritualísticas mais íntimas. Nesse tópico, será discutida a Teologia da Prosperidade como inicialmente um processo de atenção afetiva a vivência material dos fiéis, como principal responsável por desenvolver uma relação na qual existe a crença na eficácia das práticas simbólicas para resolver diretamente conflitos de ordem mundana, e estabelece uma narrativa de superação e resistência às crises socioeconômicas (Ferreira,2017). Com isso pretende-se observar como esse movimento é salutar para a narrativa política da extrema direita e como o judeu é retratado nessa ótica de prosperidade econômica.

A Teologia da Prosperidade é respaldada na crença da capacidade de ressignificação da vida dos fiéis a partir da adesão dos mesmos aos procedimentos simbólicos da comunidade, como por exemplo, a presença nos cultos e o pagamento dos dízimos. Pressupõe, portanto, que a comunidade neopentecostal não se omite das questões externas a ela, mas participa ativamente nas mesmas para garantir um potencial alinhamento com possíveis fiéis a partir de suas demandas específicas, um mercado religioso concorrencial, termo empregado por Oro (2001), pautado na prestação de serviços à disposição dessas pessoas.

De acordo com Oro (2006), tanto os católicos quanto os evangélicos acreditam na crença de que o diabo está imiscuído na vida mundana. Entretanto, os neopentecostais conservadores exageram essa ideia doravante a concepção da corrupção da ordem natural divina pelos ofícios dos espíritos diabólicos. Sendo o Diabo reconhecido como a encarnação do Mal e suas diversas representações (alcoolismo, violência doméstica, drogas entre outros) tornam-se o eixo das práticas religiosas dos integrantes dessa 
comunidade e a aniquilação desses males transcorre pela evangelização, restaurando a ordem natural divina enquanto melhora a qualidade de vida dos fiéis.

De acordo com Ferreira (2018), a secularização institucional da religião, o deslocamento da experiência religiosa para outras áreas da vida social, por meio de sua via protestante, ancorada na Teoria da Prosperidade, colocou em disponibilidade a possibilidade de congruência entre os valores religiosos e a vida pública. flexibilizando uma fronteira histórica entre religião e secularidade. As igrejas evangélicas, especialmente a IURD, absorvendo valores liberais, principalmente a questão do mérito e a busca da felicidade, desenvolvem uma espécie de religiofagia (Oro, 2002, p.321) que produz não só um campo religioso rico, absorvendo grupos de diferentes classes da sociedade, mas desenvolve um método de como lidar com a própria política, como exercer influência sobre o plano público a partir desse movimento de compreender a questão pública na esfera da fé.

David Lehmann (2006) estabelece uma relação na qual a concepção de política é tratada de forma negativa pelo público neopentecostal, enquanto os líderes participam da mesma como forma de garantir vantagem para a sua comunidade: "As an example of this ideological atonality, Latin American evangelicals vote as their pastors instruct them. This is not because of blind obedience, but because it is often to their advantage" (Lehmann,2006, pg.279). Abaixo reproduzo um trecho de carta de autoria da então deputada federal da Bahia, Tia Eron Vasconcelos, que foi publicada pelo Bispo Edir Macedo em seu blog. Ela expõe a atuação das igrejas neopentecostais como a IURD:

(...) Acabei de crer que a política não é esse inferno todo que se diz por aí. Ledo engano! Ela tem seu lado incrivelmente revelador (o qual eu gosto muito), pois não há melhor lugar para se conhecer gente do que na política!

Não adianta levar para casa, inserir na família, profissão, igreja etc., esses são lugares propícios para nos escondermos, mas na política... Ela funciona como um grande palco em que os "artistas" se apresentam com suas tendências, entretanto, ela tem a arte de evidenciar os do bem, os do mal, os com caráter, os sem nenhum caráter, os interesseiros, os mentirosos, os 
oportunistas, os traidores, os vaidosos...(Site Universal, 2016)

Portanto, as igrejas evangélicas se propõem como agentes transformadores de seu entorno se inserindo nos veículos de informação se destacando como uma alternativa não de fuga, mas de edificação do indivíduo, sua vinculação a algum segmento evangélico é o começo para a construção de sua prosperidade e estabilidade (Alves,2016). Essa inserção ativa do campo evangélico nos veículos midiáticos, as chamadas "Igrejas eletrônicas", e na vida secular desenvolve um comportamento singular em relação à própria atuação do fiel em relação ao sagrado e o profano: o fiel não evita o Diabo, não se refugia em espaços de fé, ele o combate ativamente por meio de centralizar na igreja a imagem de auxílio emocional e financeiro como de prestígio social (Oro,2006). A concepção de guerra espiritual (Gomes,2017), desenvolve uma espécie de "cruzada" contra aquilo que foi arbitrariamente categorizado como profano.

Esse mesmo modus operandi de se relacionar com o oponente espiritual é visto na figura de Steve Bannon, ex-estrategista-chefe da Casa Branca, a partir de sua própria noção de como lidar com o oponente político: "Bannon inverte a observação de Clausewitz sobre a guerra ser a política por outros meios. Para ele, a política é a guerra por outros meios. Não surpreende que ele tenha prometido que 'todo dia, todo dia, será uma batalha'"(ALEXANDER, 2018, p.1014). Essa postura é compartilhada por Macedo (1992) que compreende a questão da fé na questão da construção de uma Igreja ofensiva e não defensiva.

O reacionarismo político torna-se congruente com a guerra espiritual lançada por esse campo protestante. A intersecção dessa atuação entre a emergente visão da nova direita política e a politização da missão evangélica estabelece um debate a respeito da própria legitimidade do campo liberal-republicano, trazendo à tona projetos reacionários que prometem desenvolver uma ordem anti-iluminista. Ou seja, distante dos valores liberais clássicos pautados em liberdades civis e no Estado de Direito (Hunt,2006) e legitimada por fundamentos 
intransigentes sobre o funcionamento da própria troca de valores políticos e produção de projetos político-econômicos da sociedade:

\begin{abstract}
A primeira perversão seria da redução substantiva da potência da política. Invertendo a formulação de Rousseau, para o pensamento conservador "tomar os homens como são e as leis como podem ser" seria pensar a política de maneira realística. Nesse caso a política não seria mais do que gestão de conflitos, proposição da ordem como reposição da dinâmica da sociedade na qual está inserida (Cepêda, 2018, p.62).
\end{abstract}

O que se pretende reconhecer é a ideia de que enquanto as igrejas evangélicas fazem de forma eficiente à politização da religião, a política por outro lado é "sacralizada" a partir de discursos na mídia como os proferidos por Marcos Feliciano e Silas Malafaia e também da observação de manifestações políticas (Cruz, 2015). A forma de se fazer política, de encará-la, seriam pelas lentes desse tipo de fundamentalismo religioso e como, por consequência, esse movimento evangélico possibilita a apropriação negativa, nos casos das religiões de matriz africana e positiva em relação ao judaísmo. Um exemplo interessante é a reflexão encontrada no site da Igreja Internacional da Graça de Deus (IIGD) produzida em 2012 por André Soares:

\title{
[Título]18/09/2012 - DEVEMOS ORAR PELAS NOSSAS AUTORIDADES - PARTE I
}

Segundo a Bíblia, a nação de Israel, no princípio de sua formação política, estabeleceu-se por meio de um governo teocrático, onde todos os poderes (legislativo, executivo e judiciário) eram exercidos por intermédio dos profetas e dos juízes, que, levantados por Deus e ungidos para realizarem grandes feitos, tornavam-se líderes nos assuntos do Estado.

Movida pelo desejo de imitar os outros povos, a nação de Israel rejeitou esse modelo de governo teocrático que foi inicialmente ordenado por Deus (1 Sm 8.5). Esse apelo popular incomodou o profeta Samuel, líder da época, incitando-o a orar ao Senhor, porquanto Deus the respondeu: Ouve a voz do povo em tudo quanto te disser, pois não te tem rejeitado a ti; antes, a mim me tem rejeitado, para eu não reinar sobre ele (1 Sm 8.7). 
Então, foi estabelecida a primeira eleição, onde o povo teve a oportunidade de escolher seu representante: Saul, o primeiro monarca em Israel (1 Sm 10.20).

Na minha próxima postagem, continuarei essa história e falarei também sobre a importância das autoridades serem constituídas por Deus.

André Soares

A utilização dessa passagem bíblica é interessante para retratar essa desconfiança dos fiéis nos poderes instituídos por uma república. Essa descrença no funcionamento da política democrática por acreditar que a mesma possui uma característica inerentemente ruim é o perfil eleitoral de representantes como Bolsonaro e Trump. Nesse sentido a religiosidade adentra a arena política, pois há uma assimilação de que a forma pela qual a política é feita atualmente é perversa e contrária aos valores evangélicos. Essa lógica de privatização da política como arena de conversão e não de disputa política pode ajudar a compreender os elementos que constituem 0 imaginário neopentecostal conservador.

Outra característica interessante desse imaginário é o repúdio a religiões de matriz africana, apesar da assimilação de algumas de suas práticas, em contraposição a elevação moral do judaísmo e especialmente do judeu. No artigo publicado pelo Bispo Macedo no site oficial da IURD está representado a imagem do judeu para o neopentecostalismo conservador:

[Título] Como o judeu vê os Dízimos

Bispo, queria compartilhar com o senhor um fato muito interessante que aconteceu aqui. Uma senhora que frequenta a igreja, mas que era infiel a Deus no tocante aos dízimos, tem um cliente que é judeu.

Vendo que ele é muito rico, ela o questionou sobre os dízimos, se ele crê e pratica. A resposta dele foi um tapa de luva, pois ele disse que dar $10 \%$ é muito pouco, pois, segundo ele, dar somente o que está escrito seria como apenas cumprir um dever religioso. Ele não dá 10\%, mas $30 \%$ de dízimo! E mais, ele disse que muitas vezes, repentinamente, ele pega TUDO o que ganha e põe no Altar.

E ela o interpelou, pois, como ele ficaria, dando tudo? Ao que ele respondeu: Você acha que eu fico com menos? 
Que me faz falta? Nada disso! O Deus de Abraão multiplica muito mais.

Depois, ela questionou se ele ouvira falar do Templo de Salomão, e ele the disse que tem amigos judeus que vivem em São Paulo e que já foram no Templo, os quais Ihe asseguraram que o Deus de Israel está naquele lugar, porque tiveram uma experiência extraordinária nele.

O judeu ainda disse que ele também irá e que já está preparando uma oferta muito especial para oferecer no Templo. Ele usou a seguinte expressão: Estou preparando um lindo presente para o meu Deus!

É muito forte, bispo! Eles têm a consciência do Altar, que é nele que a vida muda, que as conquistas chegam, que tudo se transforma. Não existe a palavra impossível no Altar, nele tudo se faz possível!

A nossa oração é para que todos recebam esse mesmo entendimento e sejam ricamente abençoados.

\section{NEOLIBERALISMO E NEOPENTECOSTALISMO: COMO A NOVA DOUTRINA AJUDA A VELHA POLÍTICA}

A ampliação dos interesses privados comerciais na esfera pública representa necessariamente a sobreposição de valores de mercado na política (Wood,2007) e devido a isto, no movimento de privatização das demandas dos grupos políticos há um momento competitivo que tem como consequência uma relação caótica entre governo e oposição, como observado na relação de governos de extrema direita, de matriz neoliberal, como de Jair Bolsonaro e Benjamin Netanyahu.

A partir dessa tese, as "trincheiras ideológicas" expressadas aqui podem estar funcionando não somente em uma lógica dogmática religiosa, mas em uma lógica privatista utilitarista, na qual os valores de prosperidade, merecimento, competitividade e do enaltecimento da superação individual são os valores que norteiam as decisões políticas. Esse paralelismo aqui apresentado está relacionado com a tese de que igrejas neopentecostais proeminentes como a IURD estão desenvolvendo uma subjetividade empreendedora que auxilia na criação de um ambiente propício para uma filosofia utilitária defendida pelo neoliberalismo (Salgado e Santos,2018). 
Nesse sentido, a "guerra cultural" pode ser compreendida como uma disputa na qual o grupo que ganhar institucionalmente toma controle político não somente do governo, mas do regime democrático no geral, isto é, aparelhando as instituições republicanas para servir a seu propósito político para garantir que a concorrência esteja em uma constante desvantagem institucional, o que significa em última medida em tentar subverter a alternância de poder característica dos regimes democrático. Essa atuação pode ser exemplificada por algumas características, como por exemplo, a recusa por regulação institucional por poderes alheios às vias eleitorais,como o judiciário. Esses grupos enxergam a esfera pública como um campo de ampliação de seus valores políticos e não como um espaço de distribuição dos direitos. Acredito que o perfil descrito acima está congruente com um modus operandi do comportamento de mercado e que esse contexto influi na esfera política levando a lógica empresarial para a luta política institucional dos movimentos sociais e dos grupos reacionários, mas também para as camadas sociais por meio da ressignificação da ética religiosa, empregando estratégias de competição mercadológica na disputa pela adesão dos fiéis.

$O$ ataque às religiões afro-brasileiras, mais do que uma estratégia de proselitismo junto às populações de baixo nível socioeconômico, potencialmente consumidoras dos repertórios religiosos afro-brasileiros e neopentecostais, como querem alguns estudiosos, parece ser uma espécie de estratégia à la "cavalo de Tróia" às avessas. Combate-se essas religiões para monopolizar seus principais bens no mercado religioso, as mediações mágicas e a experiência do transe religioso, transformando-o em um valor interno do sistema neopentecostal. (Da Silva,2005, pg.152)

No Brasil, o modelo estatal tutelar corporativista de gestão econômica e social inaugurado em 1937 no Estado Novo e o liberalcomunitarismo de 1946, termo cunhado por Luís Werneck Vianna (2000), baseado na erradicação do patrimonialismo e na universalização dos direitos civis, dá lugar em 1964 a um modelo de gestão coercitiva que enfraqueceu a relação entre Estado e sindicatos e da orientação cívica do indivíduo a coletividade ou ao bem comum. Economicamente, o liberalismo passou a ser entendido por sua faceta utilitária, analisando o indivíduo a partir de seus desejos privados, 
deixando em segundo plano a faceta mais republicana do liberalismo, o que desenvolveria a doutrina econômica vigente, o neoliberalismo.

A partir do survey desenvolvido em 2014 pelo Pew Research Center, sociólogos como Ari Pedro Oro (2006) apontam dois fatores de atração para o crescimento de adeptos a partir de 1970: A adequação do neopentecostalismo a práticas religiosas já existentes no país e na América Latina, como as religiões de matriz africana e indígena e a importância dada pelo pentecostalismo em relação à ascensão social e prosperidade econômica, como expressado por Ferreira (2017). Nesse sentido, o contexto político e econômico favorece a reprodução de uma prática específica da teologia da prosperidade, esta direcionada para o engrandecimento individual do fiel e na operacionalização de uma gestão empresarial do pastor.

O neoliberalismo diferente do liberalismo clássico, não se apresenta como uma filosofia político-moral, como pelos escritos de Adam Smith (2017) ou John Locke (2019), sua principal estratégia política seria se distanciar do campo da política, ou seja, o indivíduo assumiria que estes valores são naturais tanto como a própria dinâmica do homem como empreendedor, isto é, o homo economicus é uma condição natural,portanto atemporal, e não social. De acordo com Thomas Lemke (2001) descrito por Dardot e Laval (2009), esta técnica transparece em todas as capilaridades da vida em sociedade, ela está presente no laissez-faire, nas políticas públicas e nas igrejas neopentecostais.

O neoliberalismo estabelece um regime de reciprocidade tanto com a Teologia da Prosperidade empregada nas Igrejas neopentecostais, a partir do sentido de que ele estabelece técnicas de "empoderamento" pessoal e individual, traçando a felicidade e a prosperidade em seu sentido utilitário como objetivos naturais, desenvolvendo processos nas quais esse indivíduo deve seguir para se sobressair em sua comunidade, quanto com o pensamento conservador da negação da possibilidade de construções de projetos. Na página oficial da Igreja Renascer em Cristo (IRC) é possível ver alguns projetos que representam essa filosofia empreendedora como o projeto Prosperity Coaching. 
A diferença do neoliberalismo e do conservadorismo, é que enquanto o conservadorismo fundamenta-se na diferença inata entre os grupos, o neoliberalismo, por sua vez se consolida na singularidade do indivíduo que é expressa a partir do mérito, aqueles que se ajustam a esse vocabulário se sobressaem e se tornam referências de comportamento, os que não se sobressaem tornam-se objetos de fracasso (a lógica da conversão e desconversão).

O campo das igrejas neopentecostais ou evangélicas, orientadas pela Teologia da Prosperidade, se beneficiam e estão relacionadas com o neoliberalismo como técnica intelectual, produzindo sentido para as experiências dos participantes dos cultos. O sistema de crenças neopentecostal é baseado em uma adesão voluntária as práticas do culto, e também, paradoxalmente, configurada como obrigatória dentro da instituição, sendo muitas vezes visto de forma negativa o fiel que não dá o dízimo ou dá um dízimo considerado enxuto, esse tipo de relação entre os atores pode ser comparada com o conceito de prestações totais de Marcel Mauss (2012).

\section{ISRALE IMAGINÁRIO: 0 PROCESSO DE CONVERSÃO E DESCONVERSÃO JUDAICO- NEOPENTECOSTAL}

Como abordado no tópico anterior sobre porque a conjuntura econômica neoliberal auxilia no crescimento do neopentecostalismo no Brasil, é possível, por consequência, compreender como a crise econômica e política que assola o país colaboram para 0 desenvolvimento de alianças políticas criadoras de projetos nacionais, estes últimos em sua larga medida, alimentados por radicalismos pautados em uma categorização polarizada do mundo.

A crise política e econômica vigente é oportuna para respaldar o discurso de renovação política e de limpeza moral que esses representantes empregam para colocar em desuso os valores republicanos auxiliadores na boa gestão da democracia e incutir na política o sistema de crenças e trocas estrategicamente congruentes com a ampliação de seu poder político. Não há razão para acreditar, até o momento, que as práticas religiosas, orientadas pela Teologia da Prosperidade, não poderiam ser praticadas por esses mesmos 
representantes na política, a evangelização invade a fronteira da secularidade, como já observamos no decorrer do artigo.

Portanto, a criação de alianças políticas caminhará junto com o processo de trocas espirituais, reformulação das religiosidades e no consequente esforço para desenvolver de uma comunidade de convertidos. Isto é, indivíduos originados de diferentes comunidades que se uniram inicialmente por suas próprias necessidades políticas, mas por empregarem a liturgia quanto arma política abriram um caminho para compartilhar símbolos e narrativas de ambas comunidades religiosas.

Entende-se que esse projeto político de nação, empregado por setores neopentecostais como o expressado na fala da atual ministra Damares anteriormente, é de manter um constante movimento de expansão a propagação de uma narrativa religiosa sectária na política brasileira, isto é, a revelia inclusive da própria vontade de setores neopentecostais progressistas. Portanto, é propagada a imagem do neopentecostal como pertencente a uma comunidade monolítica e disciplinada ao redor de lideranças fortes.

Parte da atração do neopentecostal conservador com o judaísmo, perpassa pela própria compreensão do papel de Israel quanto tipo ideal para projetar uma realidade pentecostal no Brasil, isto é, estabelecer um país nos moldes dessa narrativa conservadora neopentecostal por meio da própria ótica sobre o que é /srael. Portanto, esta pesquisa se trata, antes de tudo, da análise da representação dos diversos atores a respeito de outros atores e de si mesmo através do discurso que propagam. Os neopentecostais conservadores compreendem-se como referências de suas comunidades e por se projetarem quanto lideranças, tentam delimitar quais os signos que devem ser cultivados e desprezados, quando se trata de compreender seu papel na sociedade. Paralelamente, possui uma relação de disputa com religiões de matriz africana, como o candomblé e a umbanda, ou com o kardecismo, como já tratado no decorrer do artigo. Entretanto o que é de interesse aqui é compreender porque a relação com o judaísmo não é necessariamente negativa e porque algumas Igrejas inclusive compreendem esse 
"judeu" quanto uma referência positiva e inclusive almejada para seus seguidores.

Acredito, e isso ajuda a compreender melhor a hipótese central do artigo, que essa projeção estratégica do judeu quanto aliado político está relacionada com o próprio uso político que esses neopentecostais conservadores têm do que seja Israel, isto é, para conseguirem implementar o projeto político que desejam para o Brasil, eles definem uma narrativa do que seja Israel empregando elementos do imaginário do judeu conservador com suas próprias concepções litúrgicas.

Como os neopentecostais conservadores esvanecem as fronteiras da secularidade com a religião, é possível que essa empreitada política possa estar repercutindo no fazer religioso e desenvolvendo um processo de "conversão". De início isso é empregado por propósitos políticos, porém entende-se que as consequências dessa empreitada podem repercutir na própria integração de símbolos ou signos no próprio fazer religioso. O que é de interesse também para a pesquisa, porém não poderá ser debatido com a devida profundidade nesse artigo, é se esse processo seria previsto ou se seria uma consequência não intencional de uma prática política.

O desenvolvimento dessa comunidade judaico-neopentecostal está pautada na narrativa neopentecostal da ressurreição do fiel para uma vida nova, podendo ingressar, por meio de seu temor ao Pai, no Reino de Deus. O que leva a pergunta: O que é esse Reino de Deus? Praticamente é necessário ouvir os próprios neopentecostais conservadores sobre o tema. Para eles a Terra Santa é Israel: Conceitos como "Terra Prometida" e "Povo Escolhido" são repetidos diversas vezes pelos pastores em sermões e rodas de oração. O Estado de Israel se torna assim um exemplo de "benção divina" (Gherman, 2009, pág.58). Israel é a dádiva para todos os fiéis que passaram pelo processo de evangelização, é a recompensa por sua fidelidade aos ritos e crenças propagados pela narrativa do neopentecostalismo conservador.

A relação dos neopentecostais conservadores com o judaísmo perpassa por esse imaginário do judeu como o indivíduo capaz de defender a terra santa dos horrores externos. Assim, não é considerado, por exemplo, uma perspectiva humanista de Israel como 
um refúgio como foi observado na ótica do setor progressista da comunidade judaica.

Compreender porque é conveniente para o judeu conservador se relacionar com o neopentecostal conservador perpassa por um movimento similar como o visto dentro da comunidade neopentecostal: a necessidade de legitimar uma narrativa política como memória para a comunidade judaica no geral, isto é, o judeu conservador também desenvolve um movimento de ressignificação dos próprios símbolos de sua comunidade para motivos políticos, um desses símbolos é a própria História do Holocausto, como foi visto em uma observação de campo. Para o judeu conservador o neopentecostal conservador torna-se um aliado político interessante para prosseguir com seu próprio projeto político, considera-se que tanto o judeu quanto o neopentecostal conservador possuem uma narrativa política parecida, tentando projetar em suas próprias comunidades uma narrativa conservadora com propósito integrador.

De acordo com a pesquisa documental observando o discurso de referências conservadoras do sionismo no Brasil, como o representante da Associação Sionista Brasil Israel (ASBI) e também na etnografia feita da manifestação contra a recepção de Bolsonaro em frente ao clube Hebraica no Rio de Janeiro, é possível compreender de que forma os grupos conservadores e os progressistas lidam com a Histórica do Holocausto: para os conservadores o Holocausto é uma lição da necessidade de se enrijecer fronteiras contra elementos externos; para os progressistas é uma lição da necessidade de se "abrir fronteiras" traçando pontos de comum sintonia com povos marginalizados, recusando o autoritarismo como solução.

Esse mesmo processo dialético é perpassado por duas categorias analíticas desenvolvidas no decorrer da pesquisa: "Israel conservadora" dedicada a defesa do povo judaico das ameaças externas, como os palestinos, com isso é propagandeada a imagem de Israel como um "refúgio de progresso" na região, como forma de garantir a prosperidade do povo predestinado e a imagem da "Israel progressista" solidificada na necessidade de se criar uma comunidade humanitária pautada em certo aprendizado sobre a Holocausto. 
A dualidade de representações sobre Israel é derivada das contradições de possuir duas facetas de interação com a sociedade dentro das fronteiras de 1967: a primeira pautada nos anseios de se constituir um regime democrático baseado na cidadania universal e a outra face militarizada constituída pelo uso da força contra elementos considerados externos a Israel - tratamento proveniente das consequências da Guerra dos Seis Dias, como explicitado por Grinberg (2008). As Forças de Defesa de Israel (FDI) tornam-se um ator central nessa dinâmica, especialmente quando há um desbalanceamento nas relações entre as elites e os grupos sociais subordinados. A existência dessa face militarizada só é possível se for legitimada pelo regime democrático, quando não há essa legitimação, protestos públicos ocorrem, o exército perde poder e é necessário desenvolver espaços políticos para atender essas demandas (GRINBERG, 2008).

A ampliação desses espaços de demanda por populações não plenamente inseridas no contexto de cidadania significa para esses grupos uma ameaça à soberania do Estado israelense. Judeus sionistas de direita percebem essa abertura de espaço político como uma intervenção externa aos princípios norteadores do Estado Israelense como um Estado Judeu, portanto, há o apoio a FDI para conter a ampliação desses espaços de denúncia. Como as fronteiras de Israel são "ambíguas" devido à ocupação e a própria cidadania de indivíduos fora das fronteiras do Estado israelense também é ambígua, ocorre um conflito crescente de respaldo e não respaldo da autoridade israelense nesses territórios. Grupos progressistas tentam trazer essa dinâmica para o espaço democrático, enquanto grupos conservadores preferem que esses conflitos sejam resolvidos pela FDI, elegendo representantes que legitimem a atuação do mesmo nesses territórios, como Netanyahu.

Com o objetivo de compreender a articulação desse movimento de "conversão" e "desconversão" é necessário observar as similaridades entre os atores políticos que são referência tanto para os judeus quanto para os neopentecostais conservadores. A relação de Netanyahu com Bolsonaro é profundamente beneficiada por meio desse apelo a uma perspectiva de Estado pautada na segurança nacional e na perseguição a movimentos oposicionistas. A 
aproximação de ambos, as suas respectivas forças armadas demonstra uma necessidade contundente de frear o movimento de inclusão de grupos marginalizados ao título de cidadania a partir da prerrogativa de que esse movimento de inclusão é de, na realidade, de invasão. Assim, podendo provocar estragos na ordem pública, de tamanha natureza que é necessário o uso da força para conter os efeitos criminais das contradições social-econômicas, provenientes do desalento do Estado, tanto no contexto israelense quanto no brasileiro. As retaliações de Netanyahu a ataques terroristas a partir do veto a medidas assistencialistas aos palestinos, comprova como a narrativa da segurança nacional é estrategicamente manipulada para implementar medidas de isolamento e empobrecimento da população palestina (AFP, 03/05/2019). O mesmo é percebido na proposta de campanha de Bolsonaro, que apresenta uma proposta de Estado mínimo em simultaneidade com um pacote de segurança pública que se pretende ser mais rígido.

Nesse sentido, grupos judeus conservadores brasileiros, alinhados com essa questão em Israel e neopentecostais lidam com uma dinâmica similar politicamente: precisam obstruir os espaços de demanda de grupos marginalizados, travando uma guerra que ressignifica o conceito de democracia para deslegitimar seus antagonistas políticos. A relação desses judeus conservadores com os neopentecostais é bem descrita pelo diretor jurídico da Associação Sionista Brasil Israel (ASBI) (OLIVEIRA, 27/10/2018):

\footnotetext{
Para os evangélicos não há a substituição de uma fé pela outra, uma sucessão de pactos, mas sim uma integração, continuando os judeus com sua legitimidade e Israel como a terra messiânica. Logo, são grandes amigos dos judeus, e amantes de Israel. A ASBI abriu seus braços a estes que, muito mais do que os lobos humanistas em pele de cordeiro da esquerda, são os verdadeiros amigos dos judeus, dentro e fora de Israel.
}

Um exemplo desse conflito intracomunitário, pode ser observado na própria recepção do atual presidente Bolsonaro ao Clube Hebraica, em abril de 2017, no Rio de Janeiro. As campanhas progressistas, como um abaixo assinado digital de 2.500 nomes entre eles o do ex-ministro Renato Janine Ribeiro, para impedir que 
Bolsonaro discursasse dentro do clube culminaram em uma manifestação, na qual proporcionou um embate a respeito da legitimidade da aproximação do político com a comunidade judaica, a partir do próprio referencial das perspectivas em disputa sobre a memória da comunidade: um legado progressista-humanista e antiautoritário baseado na solidariedade a povos marginalizados ou na proteção do povo judeu priorizando os "interesses judaicos" para evitar a repetição da tragédia. Isto era visto nos cartazes empunhados por judeus progressistas ou pelas alegações feitas por judeus conservadores justificando seu apoio a Bolsonaro.

Portanto, o processo da narrativa judaico-neopentecostal conservadora de Israel e do Brasil, perpassa pela representação ideológica de uma ordem fundada a partir da necessidade de reduzir as transições entre grupos diversos no espaço democrático interrompendo qualquer potencial abalo aos poderes já pressupostos, pretendendo-se, de certo modo, produzir um projeto nacional pautado nesse enrijecimento dos critérios de quem pode participar dos espaços político-econômicos, enquanto reformula as próprias fronteiras das comunidades político-religiosas nesse esquema polarizado. A parte intrigante é que enquanto esse processo enrijece fronteiras democráticas, de acesso ao Estado, por grupos marginalizados ele também de certo modo facilita a transição de identidades entre grupos de similar gramática política, como é o caso dos neopentecostais e dos judeus conservadores.

\section{CONCLUSÃO}

Esse artigo pretendeu abordar temas inquietantes para 0 cenário político atual preocupando-se em utilizar a relação dos judeus e neopentecostais como um referencial possível para observar como as dinâmicas políticas, sociais e religiosas se articulam entre si desenvolvendo um movimento de exclusão e integração de membros de comunidades consideradas historicamente como incongruentes. Pretendeu-se abordar temas inquietantes para o cenário político atual, preocupando-se em utilizar a relação dos judeus e neopentecostais como um referencial possível para observar como as dinâmicas políticas, sociais e religiosas se articulam entre si em um movimento de 
exclusão e integração. A expectativa do artigo foi analisar como as tendências políticas contemporâneas, como as lutas por reconhecimento, desenvolvem novas formas de socialização baseadas no engajamento político de diversos atores antes distantes por suas fronteiras comunitárias. Em um mundo na qual não só os mercados, mas as comunidades civis se associam em um movimento que transfere lutas e projetos de poder de um país a outro, como Israel e Brasil, isto significa não só um movimento de reinvenção das identidades particulares, mas das próprias comunidades.

\section{REFERÊNCIAS BIBLIOGRÁFICAS}

AFP. Netanyahu congelará fundos para palestinos após assassinato de israelense. Veja, $2019 . \quad$ Disponível em:<https://veja.abril.com.br/mundo/netanyahu-congelara-fundospara-palestinos-apos-assassinato-de-israelense/>. Acesso em:3 maio.2019

ALEXANDER, Jeffrey. C. Vociferando contra o iluminismo: a ideologia de Steve Bannon. Sociologia \& Antropologia, v. 8, n. 3, p. 1009-1023, 2018.

ÁLVARES, D. Bolsonaro diz que veto à propaganda do Banco do Brasil foi "respeito com a população". Congresso em foco, 2019. Disponível em: < https://congressoemfoco.uol.com.br/especial/noticias/bolsonarodiz-que-veto-a-propaganda-do-banco-do-brasil-foi-respeito-com-apopulacao-veja-video/>.

ALVES, S. P. Mídia, democracia e a presença dos neopentecostais na política brasileira. Anais do $10^{\circ}$ Encontro da Associação Brasileira de Ciência Política, Belo Horizonte, v. 30, 2016.

CEPÊDA, V. A. A Nova Direita no Brasil: contexto e matrizes conceituais. Mediações-Revista de Ciências Sociais, v. 23, n. 2, p. 40-74, 2018.

CRUZ, L. C. Evangélicos farão "manifestação" em defesa do Brasil. Gazeta do Povo, 2015.Disponível em:< https://www.gazetadopovo.com.br/vida-publica/evangelicos-faraomanifestacao-em-defesa-do-brasil-f1rhia6i4n7cy2q2m3w7vwgpm/>. 
DARDOT, P.; LAVAL, C. A nova razão do mundo. Boitempo Editorial, 2017.

DW. MEC anuncia corte de $30 \%$ nos repasses a todas as universidades federais. DW, 2019.Disponível em: $<$ https://www.dw.com/pt-br/mecanuncia-corte-de-30-nos-repasses-a-todas-as-universidadesfederais/a-48566198>

FERREIRA, M. L. A moral (neo) pentecostal e a ética empreendedora: sobre a Teologia da Prosperidade e o impulso para o trabalho. Diversidade Religiosa, v. 7, n. 1, p. 88-101, 2017.

FRESTON, P. Breve história do pentecostalismo brasileiro. Em: ANTONIAZZI, Alberto et al. Nem anjos nem demônios: interpretações sociológicas do pentecostalismo. Petrópolis: Vozes, 1994.

GHERMAN, M. Deus e Diabo na Terra Santa: pentecostalismo brasileiro em Israel. WebMosaica, v. 1, n. 1, 2009.

GHERMAN, M.; KLEIN, M. Entre "conversos" e "desconversos": O caso da influência da Nova Direita Brasileira sobre a comunidade judaica do Rio de Janeiro. Estudios Sociales del Estado, v. 5, n. 9, p. 101-123, 2019.

GOMES, M. S. A "guerra espiritual" no Brasil: apropriações do imaginário religioso no pentecostalismo brasileiro. HORIZONTE Revista de Estudos de Teologia e Ciências da Religião, v. 15, n. 47, p. 1084-1085, 30 set. 2017.

GRINBERG, L. L. Israel's dual regime since 1967. MIT Electronic Journal of Middle East Studies, v. 3, p. 59-80, 2008.

HOLANDA, M. 'Não é a política que vai mudar esta nação, é a igreja', diz Damares Alves. Estadão, 2018. Disponível em<https://politica.estadao.com.br/noticias/geral,nao-e-a-politicaque-vai-mudar-esta-nacao-e-a-igreja-diz-damaresalves,70002636241>.

HUNT, L. $A$ invenção dos direitos humanos: uma história. Editora Companhia das Letras, 2009. 
LEHMANN, D. Secularism and the public-private divide: Europe can learn from Latin America. Political Theology, v. 7, n. 3, p. 273-293, 2006.

LEVITSKY, S.; WAY, L. A. Elections without democracy: The rise of competitive authoritarianism. Journal of democracy, v. 13, n. 2, p. 51-65, 2002.

LEVITSKY, S.; ZIBLATT, D. Como as democracias morrem. Editora Schwarcz-Companhia das Letras, 2018.

LOCKE, J. Dois tratados do governo civil. Leya, 2019.

MACEDO, E. M. B. A libertação da teologia. Editora Gráfica Universal, 1992.

MACEDO, B. "Eita, Lugar Bom!" Site Universal, 2016. Disponível em:< https://www.universal.org/bispo-macedo/post/eita-lugar-bom/>.

MACEDO, B. Como o judeu vê os dízimos. Site Universal, 2016. Disponível em:< https://www.universal.org/bispo-macedo/post/comoo-judeu-ve-os-dizimos/>.

MARTIN, D.; BERGER, P. Tongues of fire: The explosion of Protestantism in Latin America. Basil Blackwell, 1990.

MAUSS, M. Ensaio sobre a dádiva. Forma e razão da troca nas sociedades arcaicas. 2012.

MOUNK, Y. O povo contra a democracia: por que nossa liberdade corre perigo e como salvá-la. Editora Companhia das Letras, 2019.

OLIVEIRA, O. "A esquerda não é credora moral pelo padecimento do Holocausto" O que pensam os judeus que romperam com sua comunidade para defender Bolsonaro.

El País, 2018.2 Disponível em: <https://brasil.elpais.com/brasil/2018/10/23/politica/1540304878_51681 6.html >. Acesso em: 26 de abril 2019. 
ORO, A. P. Neopentecostalismo: dinheiro e magia. I/ha Revista de Antropologia, v. 3, n. 1, p. 071-085, 2001.

ORO, A. P. O" neopentecostalismo macumbeiro". Revista USP, n. 68, p. 319-332, 2006.

PRZEWORSKI, A. Crises of democracy. Cambridge University Press, 2019.

SALGADO, J.; DE PAULA SANTOS, L. Usos da" fé inteligente": a hermenêutica empreendedora da lurd. Comunicacao, Midia E Consumo, v. 15, n. 43, 2018.

SMITH, A. A riqueza das nações. Nova Fronteira, 2017.

SOARES, A. 18/09/2012 - DEVEMOS HORAR POR NOSSAS AUTORIDADES-PARTE 1. Site On Grace, 2012. Disponível em:< https://ongrace.com/portal/?coluna=devemos-orar-pelas-nossasautoridades-parte-1>

TV GLOBO. MEC diz que bloqueio de $30 \%$ na verba vale para todas as universidades e institutos federais. G1, 2019. Disponível <https://g1.globo.com/educacao/noticia/2019/04/30/mec-diz-quebloqueio-de-30percent-na-verba-vale-para-todas-as-universidades-einstitutos-federais.ghtml>. Acesso em:03 de maio 2019

VIANNA, L. W.; CARVALHO, M. A. R. de; BIGNOTTO, N. República e civilização brasileira. Pensar a República, p. 131-154, 2000.

WOOD, E. Capitalismo e democracia. En publicacion: A teoria marxista hoje. Problemas e perspectivas. BORON, Atilio A, 2007. 